\title{
Simulasi Sistem Purging valve Pipa Penyalur Tembakau pada Industri Rokok di PT. Djarum Kudus
}

\author{
Lukas Bambang Setyawan \\ Program Studi Teknik Elektro, \\ Fakultas Teknik Elektronika dan Komputer, \\ Universitas Kristen Satya Wacana, Salatiga \\ Email : lukas.setyawan@.uksw.edu
}

\begin{abstract}
Ringkasan
Proses pembuatan rokok di industri rokok memerlukan sistem pneumatic feeding untuk melakukan proses distribusi tembakau. Mesin yang terlibat adalah mesin feeder dan mesin maker. Tembakau sebagai bahan dasar rokok disalurkan melalui pipa dari mesin feeder menuju mesin maker. Untuk menjaga agar pipa penyalur tembakau tetap bersih tidak terdapat sumbatan atau gumpalan sisa tembakau pada pipa penyalur maka dibuat sistem purging valve. PT. Djarum Kudus menggunakan mesin feeder tipe KAR (rotary feeder). Mesin feeder KAR membutuhkan tambahan purging valve pada pipa penyalur tembakau untuk mengatasi adanya sisa tembakau yang menyumbat atau adanya gumpalan tembakau di dalam pipa penyalur. Pengendalian proses dilakukan memakai Beckhoff IPC CP6706 dengan visualisasi proses secara HMI menggunakan program TwinCat 3. Sistem purging valve telah dilakukan pengujian menggunakan simulasi dan sistem bekerja seperti yang diharapkan. Sebelum sistem purging valve direalisasikan dan dimplementasikan pada mesin sesungguhnya oleh PT. Djarum Kudus akan dilakukan penyempurnaan sistem terlebih dahulu untuk penggabungan dengan mesin lain.
\end{abstract}

Kata kunci: mesin feeder, mesin maker, sistem purging valve

\section{Pendahuluan}

Pada proses pembuatan rokok di industri rokok diperlukan sistem pneumatic feeding untuk proses distribusi tembakau. Terdapat 2 jenis mesin feeding yaitu jenis pertama mesin KAG (gravity feeder) dengan cara tembakau dicurahkan ke dalam pipa, dan jenis kedua adalah mesin KAR (rotary feeder) dengan cara tembakau dihisap dari penampungan menuju mesin maker. Pada mesin feeder jenis KAG terdapat komunikasi antara mesin feeder dengan mesin rokok (maker) yang tidak terdapat pada mesin feeder jenis KAR. Dengan demikian pada mesin KAG lebih mudah dilakukan pengosongan (flushing) pipa sehingga tidak ada tembakau tersisa di dalam pipa. Pada mesin KAR hal ini tidak dapat dilakukan sehingga diperlukan purging valve untuk proses pengosongan (flushing) sisa tembakau dalam pipa.

PT Djarum Kudus menggunakan mesin feeder jenis KAR melalui pipa penyalur tembakau langsung terhubung ke mesin maker. Pada proses feeding ketika tembakau dihisap dari mesin feeder menuju mesin maker sering terjadi penumpukan dan sumbatan sisa tembakau di dalam pipa penyalur setelah proses feeding selesai. Untuk mengatasi 
hal ini maka diperlukan penambahan sistem purging valve agar tembakau dapat tersalurkan menuju mesin maker dengan baik dan tidak terjadi penumpukan tembakau ketika proses feeding selesai. Dengan demikian proses feeding berikutnya tidak terganggu. [1]

Pembahasan dimulai dengan penjelasan sistem purging valve meliputi purging valve, mesin feeder, mesin maker, Beckhoff IPC sebagai pusat pengendali sistem, terminal IO, dan panel kontrol. Kemudian dilanjutkan dengan hasil pengujian dan diakhiri dengan kesimpulan.

\section{Sistem Purging valve}

Sistem Purging valve terdiri atas 3 bagian, yaitu : Human Machines Interface (HMI) sebagai antarmuka sistem dengan operator [2], panel kontrol serta pengkabelan inputloutput [3], dan Beckhoff Industrial Personal Computer (IPC) sebagai pengendali sistem [4],[5]. Diagram blok sistem keseluruhan dapat dilihat pada Gambar 1. Pada Gambar 1 sebelah atas adalah bagian input dan sebelah bawah adalah bagian output. Sedangkan di bagian tengah adalah pengendali sistem yaitu Beckhoff IPC.

Masalah yang dihadapi dalam proses penyaluran tembakau dari mesin feeder menuju mesin maker adalah mengatur agar sensor dapat saling berkomunikasi sehingga sisa tembakau setelah proses feeding dari mesin feeder ke mesin maker dapat dibersihkan tidak menggumpal pada pipa penyalur tembakau sebelum dilakukan proses feeding berikutnya. Komunikasi antar sensor ini sangat penting untuk menjaga agar tidak terjadi sumbatan pada pipa penyalur tembakau.

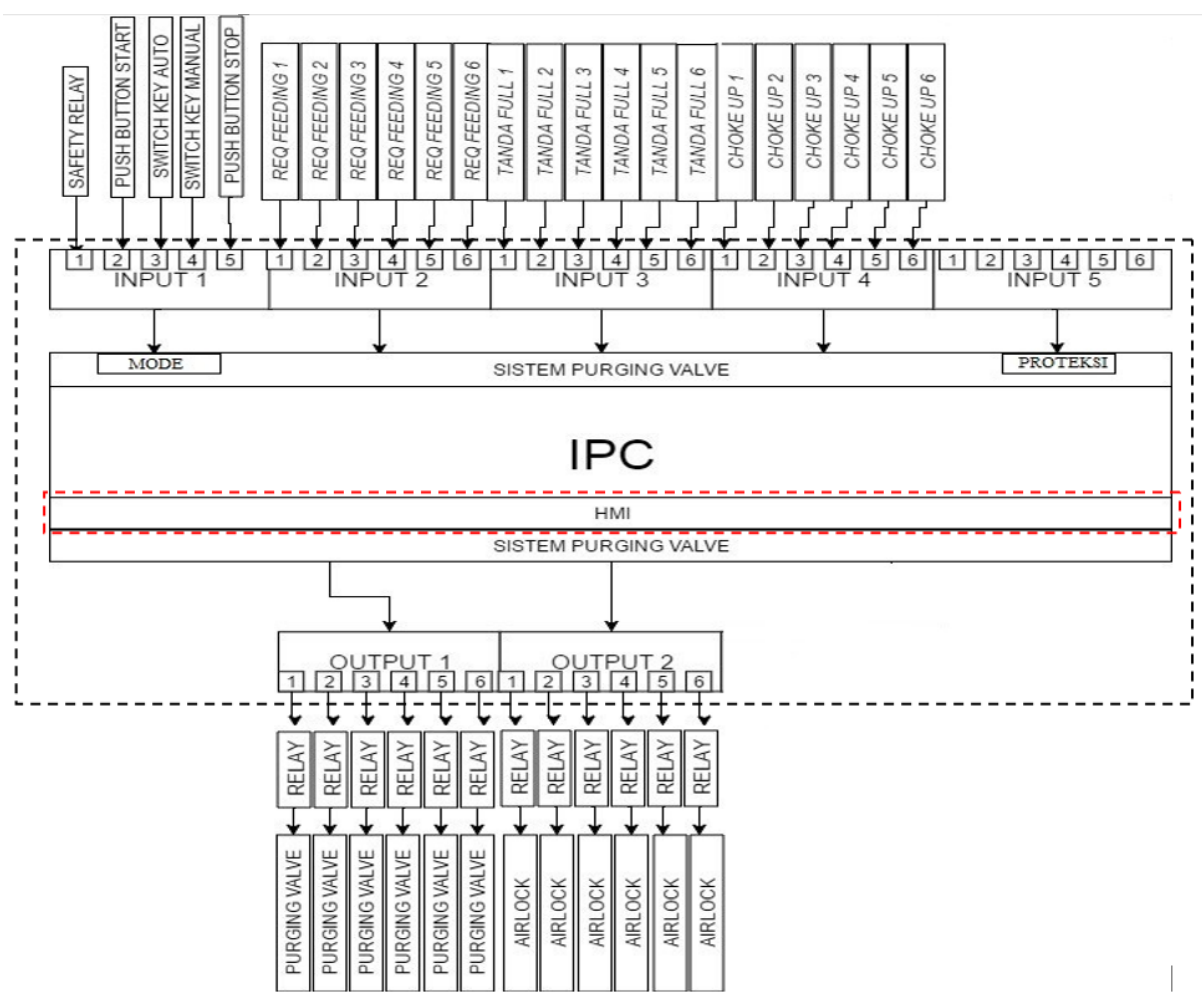

Gambar 1. Diagram Blok Sistem Keseluruhan 


\subsection{Purging valve}

Purging valve atau flap merupakan perangkat hasil modifikasi dalam suatu sistem rangkaian siklus industri dengan tujuan agar pipa penyalur tembakau dari feeder ke maker tetap bersih dan tidak terjadi sumbatan tembakau yang menggumpal di dalam pipa. Bentuk purging valve dapat dilihat pada Gambar 2. Kondisi awal purging valve dalam keadaan terbuka. Pada saat mesin maker memberi sinyal demand / request untuk menyalurkan tembakau menuju mesin maker, mesin feeder tidak langsung menyalurkan tembakau tetapi melakukan proses flushing terlebih dahulu dengan memasukkan udara melalui purging valve untuk menyapu bersih tembakau yang tersisa dalam pipa menuju ke dalam mesin maker. Selang beberapa sekon berikutnya purging valve ditutup kemudian tembakau dari mesin feeder akan disalurkan menuju ke mesin maker.

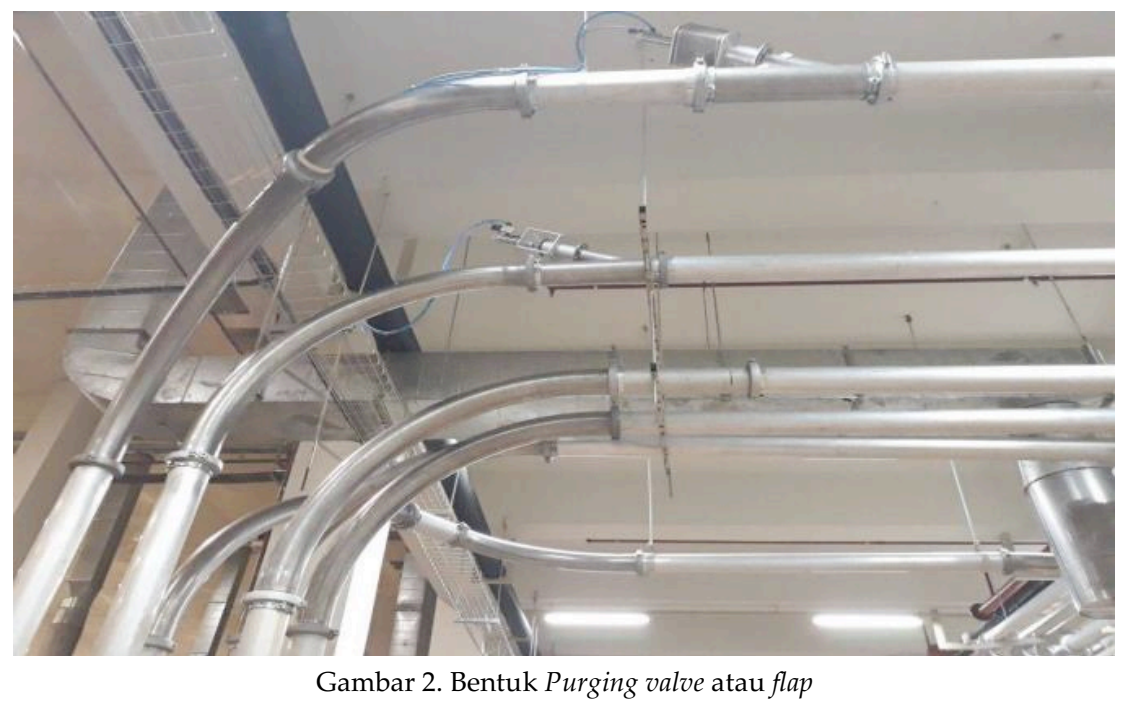

\subsection{Mesin Feeder}

Sketsa mesin feeder KAR ditunjukkan pada Gambar 3. Mesin feeder adalah mesin yang fungsinya sebagai penyedia atau penampung tembakau agar siap dihisap oleh mesin maker.

Dari Gambar 3 terlihat tembakau yang telah berada pada tahap siap hisap melalui conveyor kemudian dicurahkan ke dalam bak penampungan feeder KAR. Pada masingmasing bak penampungan terdapat 6 pipa yang digunakan untuk menyalurkan tembakau, selanjutnya tembakau tersebut akan dihisap oleh 6 mesin maker.

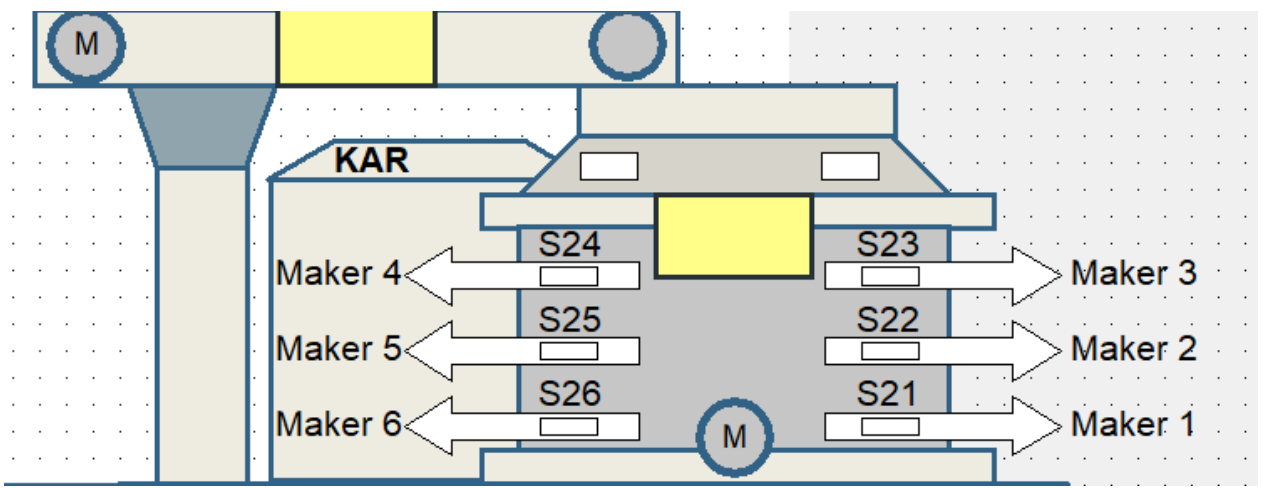

Gambar 3. Gambar sketsa mesin feeder KAR 


\subsection{Mesin Maker}

Gambar sketsa mesin maker ditunjukkan pada Gambar 4. Mesin maker adalah mesin yang berfungsi sebagai pembuat rokok. Mesin maker akan menghisap tembakau ketika mesin berada pada kondisi tembakau kosong. Dari Gambar 4 terlihat tembakau di bak penampungan mesin feeder KAR akan dihisap oleh mesin maker melalui pipa penyalur tembakau. Pada pipa penyalur tembakau tersebut dipasang purging valve yang fungsinya untuk membocorkan pipa.

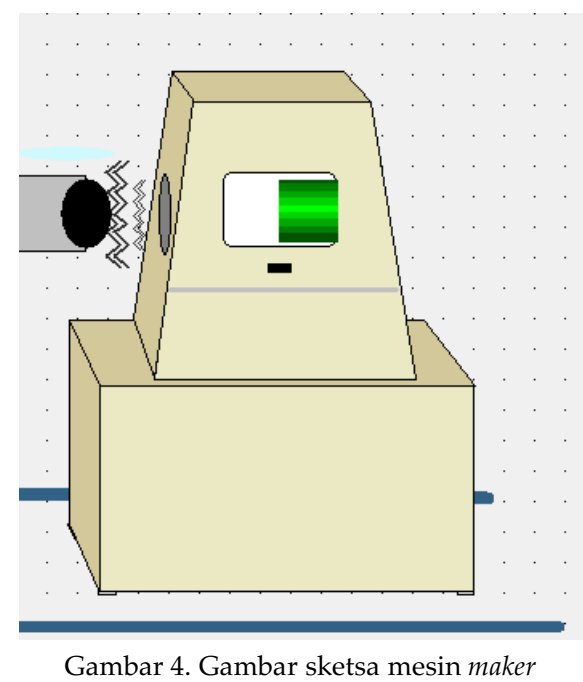

\subsection{Beckhoff IPC}

Sebagai pengendali sistem purging valve digunakan Beckhoff IPC tipe CP6706 (Gambar 5). IPC CP6706 adalah PC-based PLC (Programmable Logic Controller) sekaligus sebagai layar user interface yang terintegrasi dengan internet, IO, dan windows. IPC terhubung ke IO melalui Coupler, dalam hal ini digunakan Coupler EK1100. Pengendalian sistem purging valve dilakukan menggunakan program TwinCat 3 [6] [7].

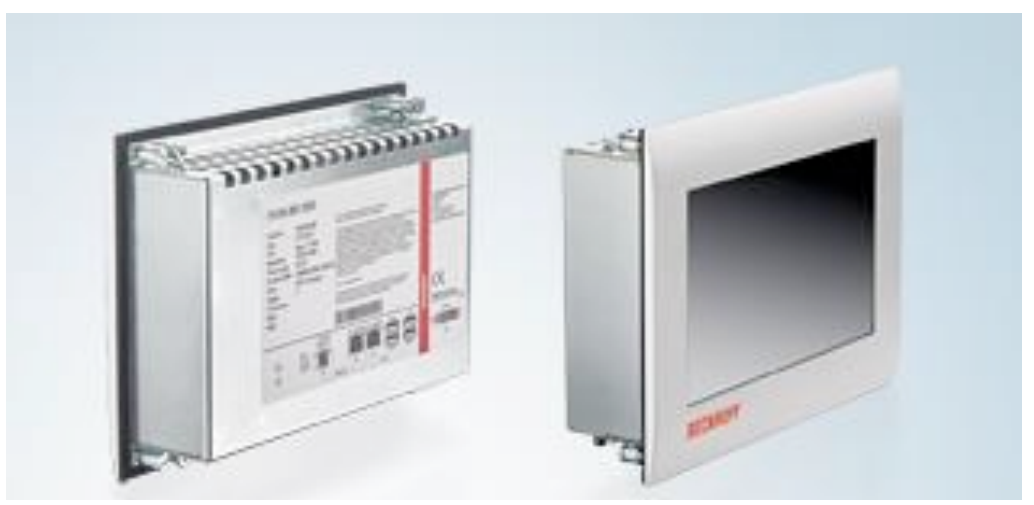

Gambar 5. Wujud Beckhoff IPC CP6706 | 7-inch "Economy” Panel PC

\subsection{Coupler EK1100}

Coupler EK1100 dapat dilihat pada Gambar 6. Coupler digunakan untuk menghubungkan EtherCAT dengan sejumlah Terminal Input dan Output. Coupler terhubung ke jaringan internet melalui antarmuka Ethernet. 


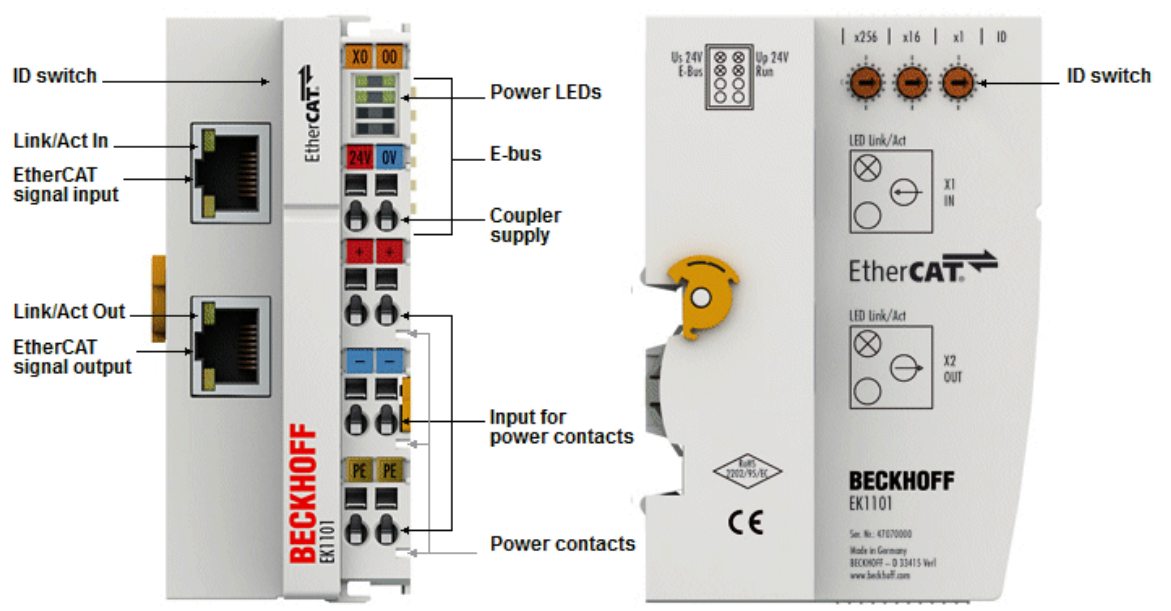

Gambar 6. Beckhoff EK1100

Tabel 1. Data Teknik Coupler EK1100

\begin{tabular}{|c|c|}
\hline Technical data & EK1100 \\
\hline Task within EtherCAT system & $\begin{array}{l}\text { coupling of EtherCAT Terminals (ELxxxx) to 100BASE-TX } \\
\text { EtherCAT networks }\end{array}$ \\
\hline Data transfer medium & Ethernet/EtherCAT cable (min. Cat. 5), shielded \\
\hline Distance between stations & $\max .100 \mathrm{~m}(100 \mathrm{BASE}-\mathrm{TX})$ \\
\hline Number of EtherCAT Terminals & up to 65,534 \\
\hline Protocol & EtherCAT \\
\hline Delay & approx. $1 \mu \mathrm{s}$ \\
\hline Data transfer rates & $100 \mathrm{Mbit} / \mathrm{s}$ \\
\hline Configuration & not required \\
\hline Bus interface & $2 \times \mathrm{RJ} 45$ \\
\hline Power supply & $24 \vee D C(-15 \% /+20 \%)$ \\
\hline Current consumption from $\mathrm{U}_{\mathrm{s}}$ & $70 \mathrm{~mA}+(\Sigma \mathrm{E}$-bus current/4) \\
\hline Current consumption from Up & load \\
\hline Current supply E-bus & $2000 \mathrm{~mA}$ \\
\hline Power contacts & $\max .24 \mathrm{VDC} / \max .10 \mathrm{~A}$ \\
\hline Electrical isolation & $500 \mathrm{~V}$ (power contact/supply voltage/Ethernet) \\
\hline Operating/storage temperature & $-25 \ldots+60^{\circ} \mathrm{C} /-40 \ldots+85^{\circ} \mathrm{C}$ \\
\hline
\end{tabular}

\subsection{Terminal Input EL1008}

Terminal Input EL1008 dapat dilihat pada Gambar 7. Sesuai dengan namanya Terminal Input merupakan bagian input untuk proses pengendalian oleh IPC. Terdapat 8 port input dengan masing-masing alamat input sesuai dengan variabel pada program TwinCat 3. Pada masing-masing port input terdapat indikator LED yang akan menyala apabila ada sinyal input masuk. 


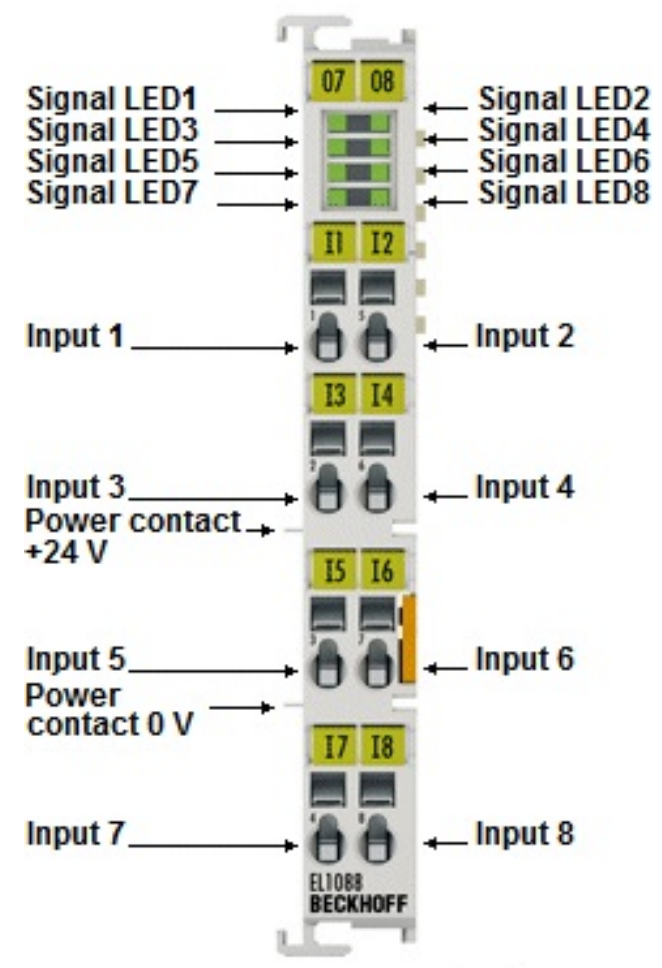

Gambar 7. Terminal input EL1008

Tabel 2. Data Teknik Terminal Input EL1008

\begin{tabular}{|l|l|}
\hline Technical data & EL1008 | ES1008 \\
\hline Connection technology & 1 -wire \\
\hline Specification & EN $61131-2$, type 1/3 \\
\hline Number of inputs & 8 \\
\hline Nominal voltage & $24 \mathrm{~V} \mathrm{DC}(-15 \% /+20 \%)$ \\
\hline "0" signal voltage & $-3 \ldots+5 \mathrm{~V}$ (EN 61131-2, type 3) \\
\hline "1“ signal voltage & $11 . .30 \mathrm{~V}$ (EN 61131-2, type 3) \\
\hline Input current & typ. $3 \mathrm{~mA}$ (EN 61131-2, type 3) \\
\hline Input filter & typ. $3.0 \mathrm{~ms}$ \\
\hline Distributed clocks & - \\
\hline Current consumption power & typ. $2 \mathrm{~mA}+$ load \\
\hline contacts & typ. $90 \mathrm{~mA}$ \\
\hline Current consumption E-bus & $500 \mathrm{~V}$ (E-bus/field potential) \\
\hline Electrical isolation & 8 inputs \\
\hline Bit width in the process image & no address or configuration setting \\
\hline Configuration & standard input terminal for bouncing signals (filter 3 ms) \\
\hline Special features & approx. $55 \mathrm{~g}$ \\
\hline Weight & \\
\hline
\end{tabular}




\subsection{Terminal Output EL2008}

Terminal Output EL2008 seperti Gambar 8. Terminal output digunakan sebagai port keluaran hasil proses pengendalian oleh IPC seperti eksekusi kontrol ke perangkat keras relay atau LED. Terdapat 8 port keluaran dan setiap port memiliki indikator LED yang akan menyala bila ada sinyal keluaran.

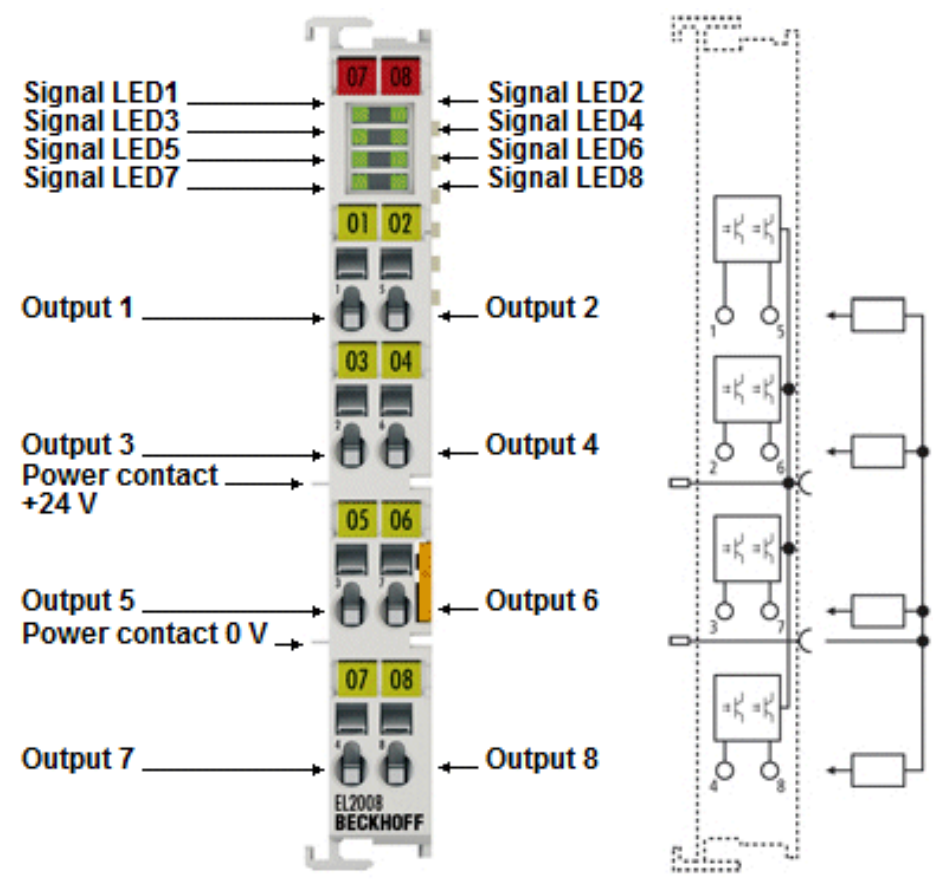

Gambar 8. Terminal Output EL2008

Tabel 3. DataTeknik Terminal Output EL2008

\begin{tabular}{|l|l|}
\hline Technical data & EL2008 | ES2008 \\
\hline Connection technology & 1 -wire \\
\hline Number of outputs & 8 \\
\hline Rated load voltage & $24 \mathrm{~V} \mathrm{DC}(-15 \% /+20 \%)$ \\
\hline Load type & ohmic, inductive, lamp load \\
\hline Distributed clocks & - \\
\hline Max. output current & $0.5 \mathrm{~A}$ (short-circuit-proof) per channel \\
\hline Short circuit current & typ. $<2 \mathrm{~A}$ \\
\hline Reverse voltage protection & yes \\
\hline Breaking energy & $<150 \mathrm{~mJ} / \mathrm{channel}$ \\
\hline Switching times & typ. Ton: 60 Hs, typ. ToFf: $300 \mu$ s \\
\hline Current consumption E-bus & typ. $110 \mathrm{~mA}$ \\
\hline Electrical isolation & $500 \mathrm{~V}$ (E-bus/field potential) \\
\hline $\begin{array}{l}\text { Current consumption power } \\
\text { contacts }\end{array}$ & typ. $15 \mathrm{~mA}+$ load \\
\hline Bit width in the process image & 8 outputs \\
\hline \hline
\end{tabular}




\subsection{Panel Kontrol}

Sketsa panel kontrol dapat dilihat pada Gambar 9. Sedangkan tampak depan panel kontrol ditunjukkan pada Gambar 10. Tampak bagian dalam panel kontrol dapat dilihat pada Gambar 11. Tampak bagian dalam pintu panel kontrol diperlihatkan oleh Gambar 12.

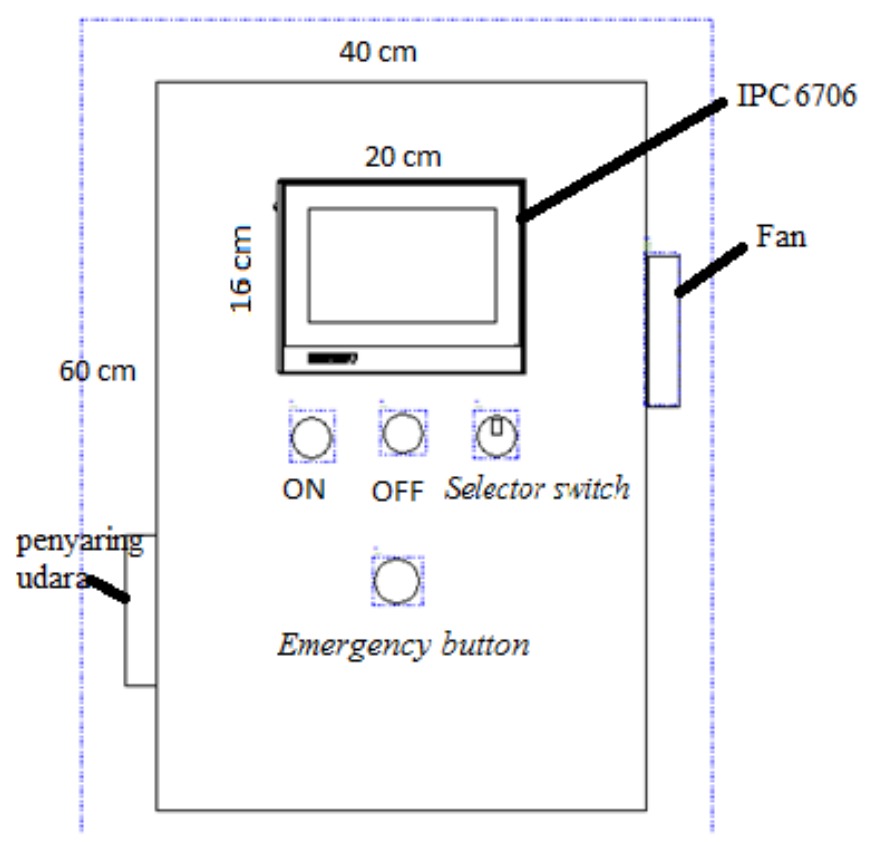

Gambar 9. Sketsa Bagian Depan Panel Kontrol

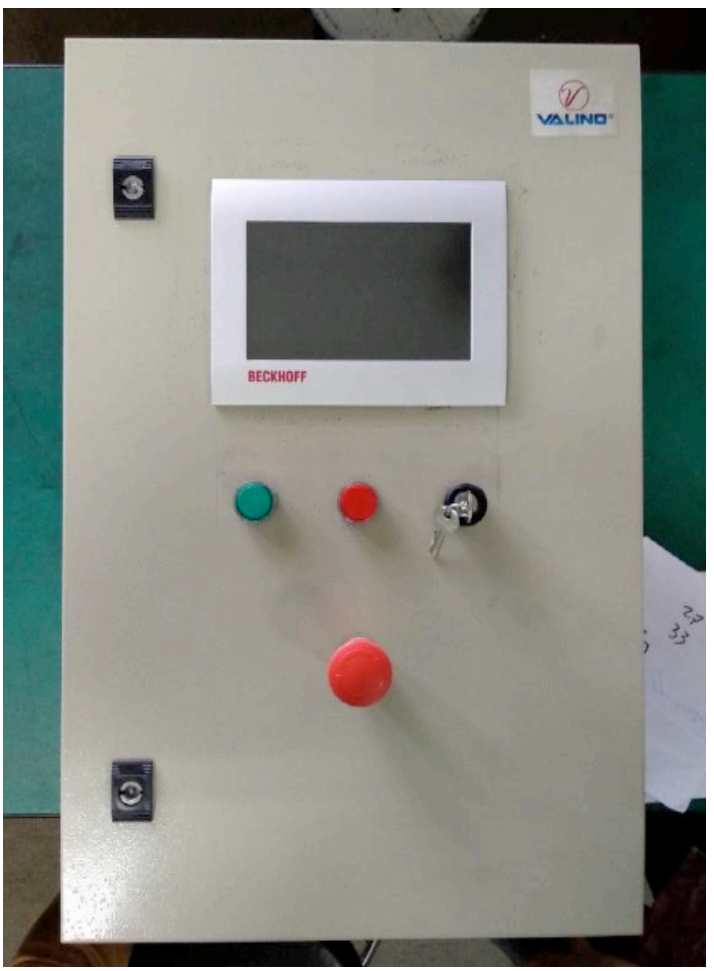

Gambar 10. Tampak Depan Panel Kontrol [3] 


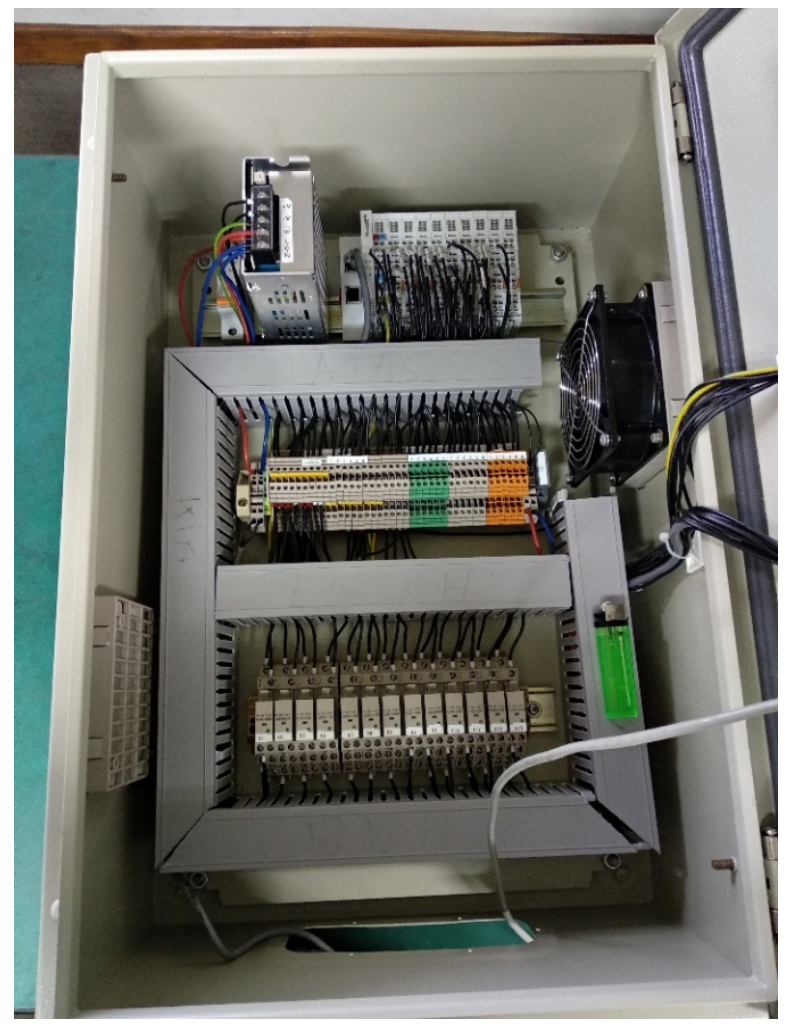

Gambar 11. Tampak Bagian Dalam Panel Kontrol [3]

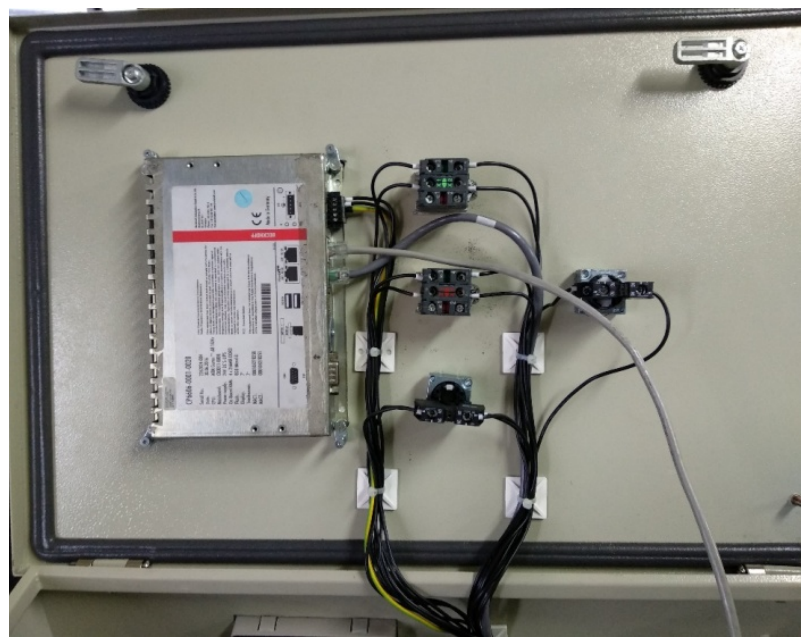

Gambar 12. Tampak Bagian Dalam Pintu Panel Kontrol [3]

\section{Perangkat Lunak Sistem}

Implementasi perangkat lunak sistem Purging valve menyediakan 2 pilihan, yaitu : mode Manual dan mode auto. Mode auto dilengkapi dengan proteksi ketika berada pada kondisi choke up dan full.

Bagan sistem mode manual digambarkan oleh Gambar 13. Sedangkan bagan sistem auto dan proteksi diperlihatkan pada Gambar 14. 


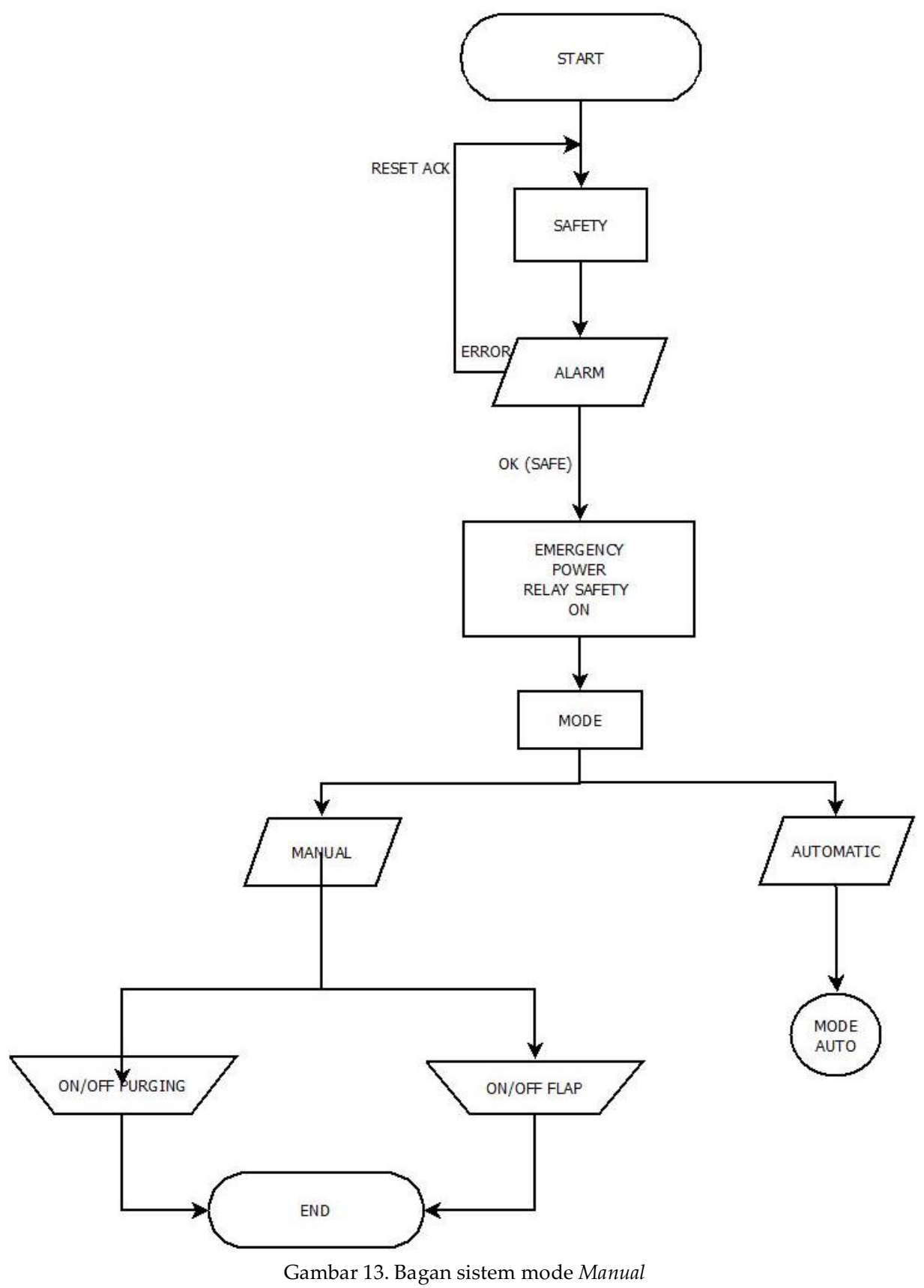




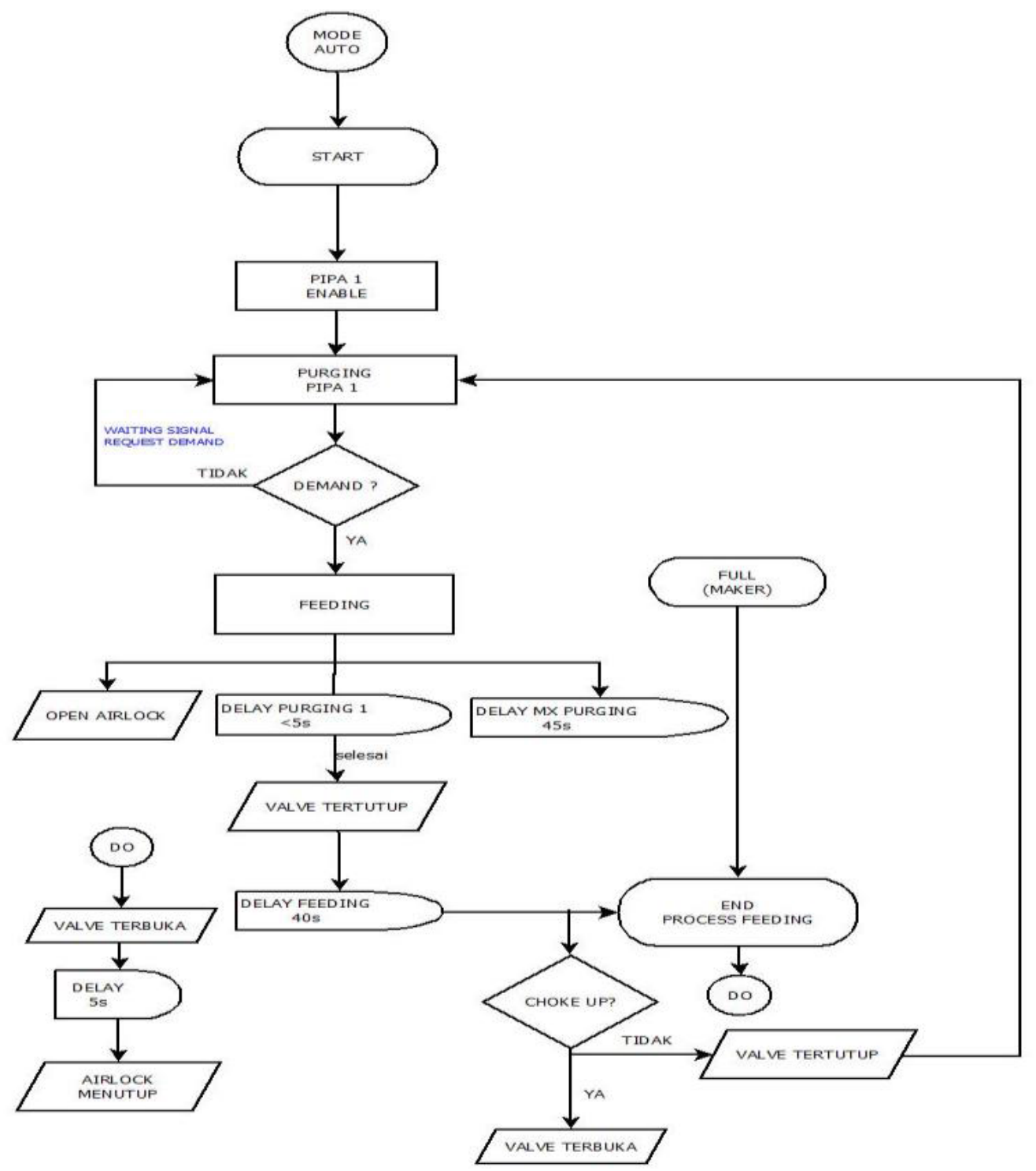

Gambar 14. Bagan sistem mode Auto dan Proteksi

\section{Hasil Pengujian}

Pengujian sistem dilakukan menggunakan simulasi untuk menjalankan sistem purging valve dengan memanfaatkan fitur Visualization pada aplikasi TwinCat 3 yang dapat digunakan untuk membuat Human Machine Interface (HMI). Semua data nilai variabel disimulasikan menggunakan Visualization untuk menggantikan sinyal masukan dari HMI (seperti fitur enable tiap pipa, tombol pilihan mode, pengaturan airlock dan flap) serta dapat melihat / memonitor secara visual kondisi dari airlock dan flap purging sedang terbuka atau tertutup dengan cara mengambil nilai dari variabel-variabel dari algoritma masing-masing pipa. Implementasi perangkat lunak sistem Purging valve menyediakan 2 pilihan, yaitu : mode Manual dan mode Auto. Mode Auto dilengkapi dengan proteksi ketika berada pada kondisi choke up dan full. 


\subsection{Simulasi pengujian Mode Manual}

Pengujian mode manual dilakukan pada 3 kondisi dengan cara mengambil nilai dari variabel-variabel untuk kendali airlock dan flap purging. Sinyal masukan yang berasal dari HMI digantikan oleh tombol/button yang dimasukkan dalam bentuk simbol pada simulasi dan mengalami perubahan warna jika nilai dari variabel tersebut mengalami perubahan. Nilai dari variabel apabila True memiliki nilai 1 (hijau), dan False memiliki nilai 0 (merah). Contoh tampilan hasil pengujian dapat dilihat pada Gambar 15.

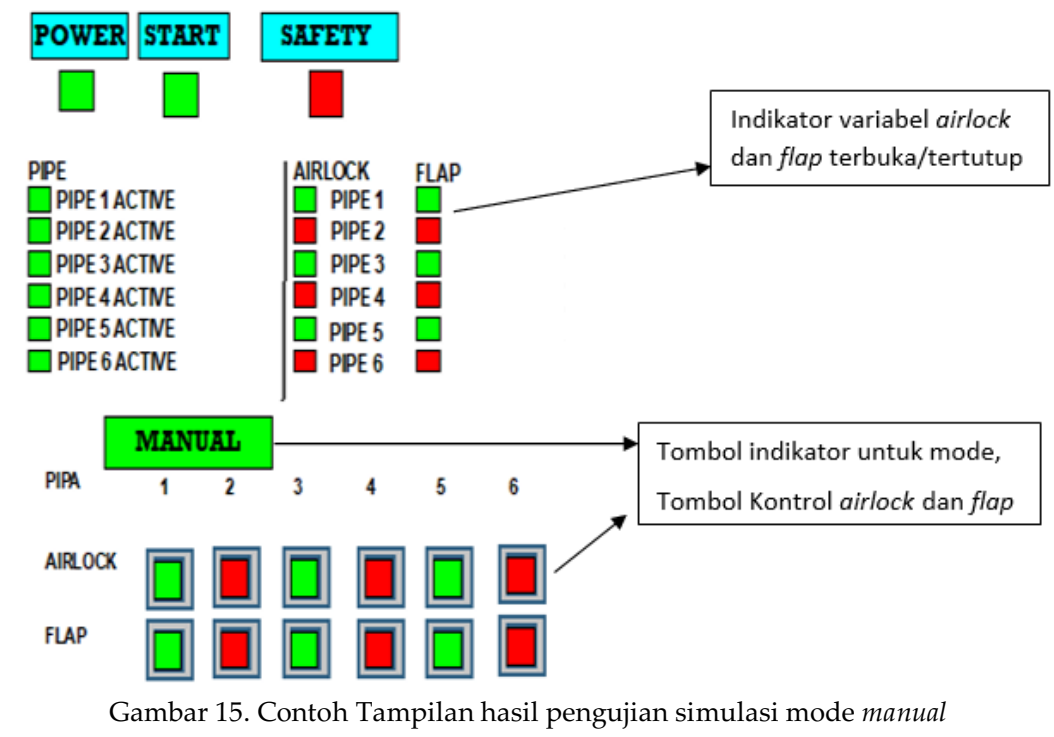

1. Pengujian kondisi pertama, simulasi dilakukan untuk menjalankan sistem mode manual dengan mengaktifkan airlock dan flap pipa 1. Tombol Power dan Start ditekan sehingga bernilai true. Kemudian simulasi dilakukan untuk mengaktifkan mode manual, airlock dan flap pipa 1. Ketika tombol manual, airlock dan flap pipa 1 ditekan, maka variabel output airlock dan flap untuk pipa 1 tersebut bernilai true(1) dan pipa lain bernilai false ketika tidak ditekan.

2. Pengujian kondisi kedua, simulasi dilakukan seperti pengujian pertama namun ditambah dengan penekanan pada tombol airlock dan flap pipa 3. Output dari variabel airlock dan flap untuk pipa 1 dan pipa 3 bernilai true(1), dan pipa lain bernilai false ketika tidak ditekan.

3. Pengujian kondisi ketiga, simulasi dilakukan seperti pengujian kondisi pertama dan kedua namun ditambah dengan penekanan pada tombol airlock dan flap pipa 5. Output dari variabel airlock dan flap untuk pipa 1, pipa 3, dan pipa 5 bernilai true(1), dan pipa lain bernilai false ketika tidak ditekan. 


\subsection{Simulasi pengujian Mode Auto}

Pengujian algoritma mode auto disimulasikan pada 1 pipa dengan 1 kondisi normal dan 2 kondisi proteksi. Contoh tampilan hasil pengujian diperlihatkan pada Gambar 16.

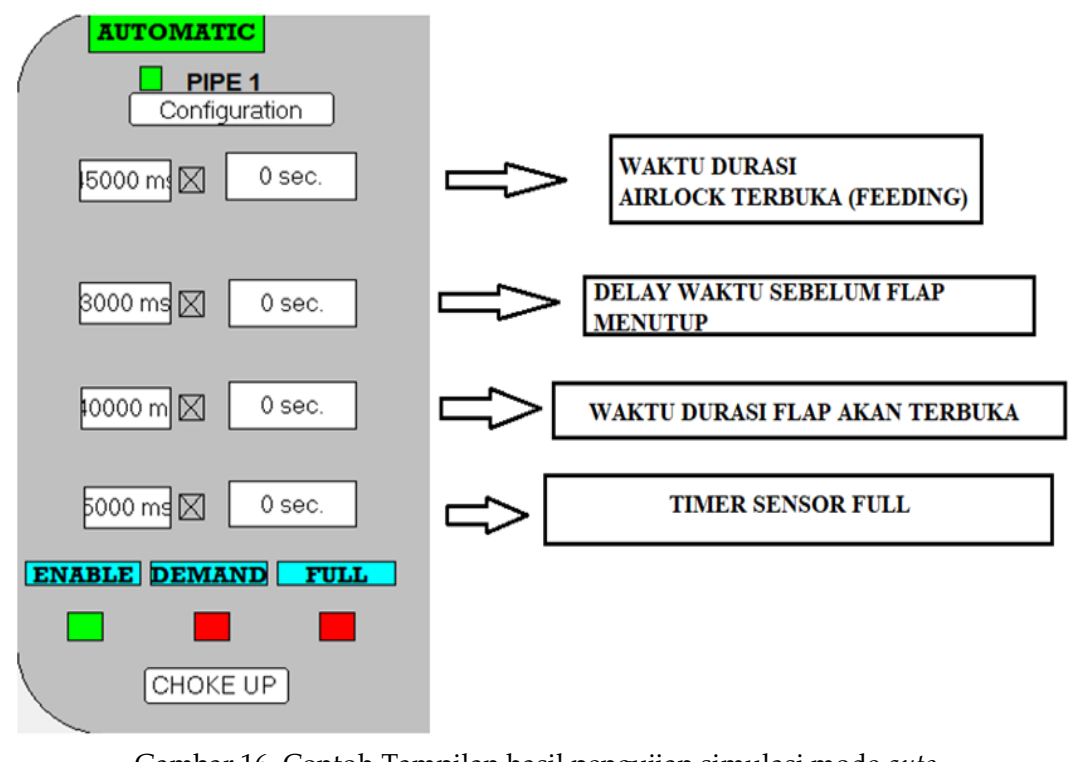

1. Pengujian pertama

a. Simulasi dilakukan untuk mode auto dengan kondisi awal sensor request feeding menyala menandakan bahwa mesin maker membutuhkan tembakau, lalu timer 45 sekon akan bekerja seiring dengan menyalanya indikator variabel airlock pipa 1 yang menandakan bahwa sedang ada hisapan namun flap pipa 1 masih terbuka, proses ini dinamakan proses flushing (variabel flap bernilai 0 ).

b. Setelah 3 sekon berlalu, variabel timer 3 sekon yang aktif tersebut akan mentrigger timer 40 sekon seiring dengan aktif nya indikator flap purging pipa 1 yakni flap berada pada posisi tertutup (variabel bernilai 1). Ini menandakan proses feeding mulai berjalan.

c. Setelah timer 40 sekon selesai, maka flap purging akan terbuka (variabel bernilai 0) yaitu proses flushing terjadi. Setelah 3 sekon, airlock akan mati menandakan proses feeding telah berhenti dan tidak terdapat hisapan.

2. Pengujian kedua, proteksi sensor full

a. Simulasi dilakukan sama seperti simulasi pada pengujian pertama pada mode auto, namun di tengah berjalannya proses feeding, sensor full akan diaktifkan dan variabel sensor full akan aktif, yang menandakan bahwa tembakau pada mesin maker sudah penuh.

b. Setelah sensor full terdeteksi, flap akan terbuka yang menandakan telah memasuki proses end feeding lalu setelah 5 sekon proses flushing tersebut, maka dapat dilihat bahwa airlock akan menutup/berhenti menghisap.

3. Pengujian ketiga, proteksi choke up

a. Simulasi dilakukan sama seperti pada pengujian kedua, namun indikator chokeup ditekan sebagai simulasi terjadi sinyal chokeup. 
b. Ketika proses feeding sedang berjalan, disimulasikan tombol chokeup diaktifkan, flap purging akan terbuka (variabel bernilai 0) selama 1 sekon dan kembali tertutup/menyala melanjutkan proses feeding.

\section{Kesimpulan}

Perancangan sistem purging valve telah dilakukan. Pengujian sistem secara simulasi menunjukkan bahwa sistem purging valve bekerja seperti yang diharapkan, baik mode manual maupun mode auto. Sistem purging valve melibatkan mesin feeder KAR dan mesin maker. Sistem dikendalikan oleh Beckhoff IPC tipe CP6706 dengan visualisasi proses secara HMI menggunakan program TwinCat 3.

Berikutnya pihak PT. Djarum Kudus masih akan melakukan penyempurnaan sistem dan penggabungan dengan panel mesin yang lain sebelum melakukan realisasi dan implementasi serta instalasi pada sistem keseluruhan.

\section{Daftar Pustaka}

[1] S. V. Iriyanto, "Sistem Purging valve untuk 6 Pipa Penyalur Tembakau pada Industri Rokok di PT Djarum Kudus," Skripsi, Fakultas Teknik Elektronika \& Komputer, Universitas Kristen Satya Wacana, Salatiga, Januari 2019.

[2] J. Alvin, "Human Machines Interface Sistem Purging valve Pada Pipa Penyalur Tembakau di PT Djarum Kudus," Skripsi, Fakultas Teknik Elektronika \& Komputer, Universitas Kristen Satya Wacana, Salatiga, Juli 2018.

[3] S. Ardian, "Panel Kendali 6 Pipa Untuk Menyalurkan Tembakau Dari Mesin Feeder Menuju Mesin Maker pada Industri Rokok di PT Djarum Kudus," Skripsi, Fakultas Teknik Elektronika \& Komputer, Universitas Kristen Satya Wacana, Salatiga, September 2018.

[4] https://download.beckhoff.com/download/Document/automation/twincat3/TC1300_ C_EN.pdf [Accessed : 5 Maret 2018]

[5] Beckhoff, "Installation and Operating instructions for CP6600",version 1.3, Built-in Panel PC, Beckhoff Automation GmbH \& Co. KG, Huelshorstweg 2033415 Verl, Germany, 2017.

[6] Beckhoff, "TwinCat 3 Training: Basic PLC Programming, TR3020", Beckhoff Automation GmbH \& Co. KG, Huelshorstweg 2033415 Verl, Germany, 2017.

[7] Beckhoff, "TwinCat 3 Training: Basics TwinCat HMI, TR7050", Beckhoff Automation GmbH \& Co. KG, Huelshorstweg 2033415 Verl, Germany, 2017. 